\title{
Insulin like growth factor-l in acute subarachnoid hemorrhage: a prospective cohort study
}

Stepani Bendel*1, Timo Koivisto2, Olli-Pekka Ryynänen³, Esko Ruokonen'1, Jarkko Romppanen, Vesa Kiviniemi5 and Ari Uusaro'

\begin{abstract}
Introduction: Neuroendocrine deficiencies may affect recovery after aneurysmal subarachnoid hemorrhage (aSAH). Insulin like growth factor-I (IGF-I) regulates neuronal growth and apoptosis in ischemic stroke. Our study was designed to a) characterize the behavior of serum IGF-I and growth hormone $(\mathrm{GH})$ in the acute and late phases after aSAH reflecting possible pituitary gland function and b) evaluate the association between IGF-I and morbidity assessed by Glasgow outcome scale (GOS) and health related quality of life (HRQoL) in patients with aSAH.

Methods: In this prospective cohort study, patients with aSAH $(n=30)$ were compared to patients who underwent elective aneurysm surgery $(n=16)$. Serum GH and IGF-I concentrations were measured daily for five (controls) or seven (aSAH) days and at three months. GOS and 15d HRQoL was measured at three months. A mixed models method was used for testing between the groups. For factors possibly affecting HRQoL in aSAH patients, we constructed a Bayesian predicting model using a P-course Bayesian classifier.

Results: The mean IGF-I concentrations for days one to five were $8.1 \pm 3.5 \mathrm{nmol} / \mathrm{l}$ in patients with aSAH and $11.2 \pm 3.1$ in the control group $(P=0.01)$. No corresponding difference was found at three months. Serum GH concentrations were similar in both patient groups. Severity of the aSAH did not affect serum IGF-I concentrations. Patients with GOS $\leq$ 4 had lower IGF-I concentrations and lower HRQoL than patients with GOS $5(P=0.02$ and 0.003 respectively). The 15d HRQoL was $0.81 \pm 0.16$ in patients with aSAH and $0.86 \pm 0.09$ in control patients $(P=0.24)$. In the Bayesian model, the use of statins prior to aSAH, hyponatremia, high maximal sequential organ specific score (SOFAmax), and low cumulative IGF-I concentrations on days one to seven were associated with poor HRQoL (accuracy 89\%, sensitivity $86 \%$, and specificity 93\%).
\end{abstract}

Conclusions: IGF-I concentrations are low during acute aSAH, which may have an impact on morbidity.

Trial registration: ClinicalTrials.gov Identifier NCT00614887

\section{Introduction}

Acute aneurysmal subarachnoid hemorrhage $(\mathrm{aSAH})$ is a devastating disease, annually affecting 9 in 100,000 people [1]. The outcome of aSAH may be affected by major neurological deficits and cardiovascular, endocrinological, or psychological disorders. Neuroendocrine deficiencies may also affect recovery and rehabilitation after aSAH. Endocrinological disturbances may develop because of the proximity of the hypothalamus and hypophysis to sensitive vascular structures, which can be

* Correspondence: Stepani.Bendel@kuh.fi

1 Department of Intensive Care, Kuopio University Hospital and University of Eastern Finland, PL 1777, 70211 Kuopio, Finland

Full list of author information is available at the end of the article affected by acute aSAH. Hydrocephalus, local hemorrhages, microinfarctions, venous stasis, vasospasm, and surgical manipulation may also cause dysfunction of the pituitary gland and/or hypothalamus [2].

Some studies suggest the hypothalamo-pituitary-adrenal (HPA) axis may already be affected in the acute phase of aSAH [2-6]. Several studies have revealed that, at least in the late phase, aSAH may present with a pituitary insufficiency $[2,4,7,8]$. Growth hormone (GH) deficiency is the most common single pituitary hormone deficit in patients with traumatic brain injury (TBI) and aSAH $[4,8]$. In patients with aSAH, GH deficiency may affect the quality of life [9]. GH mediates its action via insulinlike growth factors (IGF-I). IGF-I has potential effects on 
neuronal growth but also on neuronal cell death, apoptosis and neuromodulation [10-12], which play a major role in ischemic stroke and in the pathological cellular processes of aSAH [13]. Levels of IGF-I are low during the acute phase of critical illness [14]. Recent studies suggest low IGF-I levels may negatively affect outcome, at least in patients with ischemic stroke [15-17], and low IGF-I values in patients with hemorrhagic stroke may be associated with excess mortality [17].

There is no data available on the behavior of serum IGF-I concentrations in the acute phase of aSAH. The aim of our study was to characterize the behavior of IGFI and GH acutely and three months after aSAH. This may reflect acute pituitary function. Additionally, we hypothesized that low cumulative IGF-I concentrations may negatively influence morbidity assessed by Glasgow outcome scale (GOS) and health-related quality of life (HRQoL).

\section{Materials and methods}

All patients aged 18 years or over and scheduled for an elective open surgical aneurysm treatment (control group), and all patients with aSAH admitted to Kuopio University Hospital in Finland between 29 March and 30 November 30, 2006 were prospectively assessed for eligibility for this study. Patients with an elective endovascular management of their unruptured aneurysm were excluded from the control group because of their expectedly short hospital stay. This study's patient population is the same as that used in a previous publication [3]. The exclusion criteria were: any known pituitary insufficiency, use of etomidate before study entry or during the study period, unknown exact bleeding day, bleeding more than three days before inclusion, previous aSAH, and moribund state of the patient.

The hospital ethics committee approved the study protocol and informed written consent was received from the patients or their next of kin.

\section{Patients with aSAH}

The following blood samples were collected from the first to seventh mornings following bleeding: serum (s) GH (reference value 0 to $11.5 \mathrm{mU} / \mathrm{l}$ ), serum IGF-I (reference values: 15 to $45 \mathrm{nmol} / \mathrm{l}$ for age 21 to 30 years; 14 to 36 $\mathrm{nmol} / \mathrm{l}$ for age 31 to 50 years; ages 10 to $29 \mathrm{nmol} / \mathrm{l}$ for age 51 to 70 years; and 8 to $23 \mathrm{nmol} / \mathrm{l}$ for age over 70 years). In control patients, the corresponding blood samples were collected from the first to fifth postoperative days after the patients were discharged. Additional routine laboratory parameters, such as electrolytes, were collected on a daily basis.

\section{Follow up at three months}

At the scheduled three-month follow-up visit, serum GH and serum IGF-I samples were collected at $9 \mathrm{am}$. In addi- tion, the patients (or their relatives) were asked to fill out a 15D quality of life questionnaire [18]. We used agematched and sex-matched IGF-I-concentrations as indicators for low IGF-I and suspected GH deficiency. We also used levels of IGF-I less than $11 \mathrm{nmol} / \mathrm{l}$ [19] as the cut off for low IGF-I. Samples of serum GH and serum IGF-I were stored at $-70^{\circ} \mathrm{C}$ for analysis. The same personnel performed all analyses in one laboratory at the Kuopio University Hospital. Serum GH concentrations were analyzed with specific time-resolved fluoroimmunoassay by AutoDelfia (PerkinElmer Life and Analytical Sciences Wallac Oy, Turku, Finland). Serum IGF-I concentrations were analyzed using a quantitative sandwich ELISA technique (Quantikine Human IGF-1 Immunoassay; R\&D Systems, Minneapolis, MN, USA).

\section{Quality of life assessment}

The HRQoL was measured by the $15 \mathrm{D}$ scale $[18,20]$. The $15 \mathrm{D}$ is a generic and standardized HRQoL instrument consisting of 15 dimensions: mobility, vision, hearing, breathing, sleeping, eating, speech, elimination, usual activities, mental functioning, discomfort and symptoms, depression, distress, vitality, and sexual activity. Each dimension has five grades of severity. For each dimension, the respondent must choose one of the five levels that best describes his or her state of health at the moment (best level $=1$; worst level $=5$ ). The results of 15D can be presented as a single index or as a profile of all 15 dimensions. A change of 0.02 to 0.03 points in the health utility index or 15D score is considered to be clinically noteworthy. The values on a 0 to 1 scale reflect the levels of the dimension, with 1 corresponding to no problems with the dimension and 0 to being dead. The mean score of the Finnish population aged 50 to 59 years was 0.92 (0.91 to 0.92) [21]. In this study, HRQoL-indexes were classified into three groups: 0.8 to $1.0=$ normal, 0.6 to $0.79=$ limited, and less than $0.6=$ poor HRQoL .

\section{Statistical methods}

We used a power of $80 \%$ and a two-sided $\alpha$-level of 0.05 in sample size calculations. We assumed that $25 \%$ of patients with aSAH and none of the elective surgical patients would develop pituitary insufficiency measured by low IGF-I. Data are presented as mean \pm standard deviation, absolute values and percentages, or medians and interquartile ranges. Distribution of the data was assessed by the Kolmogorov-Smirnov test. For normally distributed parameters, student's t-tests were used to compare the means of different groups. The Mann-Whitney $U$ test was used for nonparametric testing between the groups. A mixed models method was used to test between groups, allowing heterogeneity between the groups. To identify the factors associated with poor HRQoL or death, we used a Bayesian predicting model in 
aSAH patients. This was performed using P-course Bayesian classifier [22].

P-course is a web-based Bayesian classifier that is able to use multidimensional priors, for example separate priors for the outcome variable, in general, and for the outcome variable according to each predicting variable. The methods have equaled or outperformed novel logistic regression, especially in small data sets, in terms of prediction accuracy [23], variable selection, and multiple performance measures. They can perform well with incomplete or complex data typical to small data sets. Modeling of this data was made without informative $a$ priori information.

The outcome variable was poor HRQoL measured by $15 \mathrm{D}$ and dichotomized into normal (0.80 to 1.00$)$ or poor ( 0 to 0.79 ), where the value 0 indicated death. In the first phase, there were 355 potential predicting variables. By using P-course classifier, this was reduced to 22 variables from 30 aSAH patients. To avoid over-fitting the model, we formed four randomly selected sets of 25 patients, and a prediction model was performed for each set. We obtained four slightly different sets of prediction variables.

\section{Results}

We recruited 30 patients with aSAH and 16 control patients who underwent elective aneurysm surgery. We were unable to recruit the planned 30 control patients because endovascular aneurysm treatment was frequently chosen [3]. Demographic patient data are presented in Table 1.

Seventeen patients with aSAH underwent endovascular treatment and 13 patients had open surgery. The mean length of stay (LOS) was $97 \pm 100$ hours at the ICU and $34 \pm 51$ hours at the high-dependency unit (HDU) in patients with aSAH. Patients in the control group had an HDU LOS of $22 \pm 2$ hours. Patients with aSAH had a hospital LOS of $14.6 \pm 5.4$ days, and patients in the control group of $8 \pm 3$ days $(P<0.001)$. The three-month mortality was $10 \%$ in patients with aSAH. None of the patients in the control group died.

Serum IGF-I concentrations are presented in Figure 1. IGF-I levels were significantly lower in patients with aSAH than in control patients on days one to five $(P=$ 0.01 ), but no difference was found at three months follow up (Table 2). The mean IGF-I concentration for days one to five was $8.1 \pm 3.5 \mathrm{nmol} / \mathrm{l}$ in patients with aSAH and $11.2 \pm 3.1$ in the control group. Serum GH concentrations were similar in patients with aSAH and control patients. Serum GH and IGF-I did not correlate at any time point in patients with aSAH or in the control group.

Figure 2 represents the pooled distribution of IGF-I in respect to different cut-off levels.
No statistically significant differences were found in the proportion of having lower than age-related IGF-I reference values between patients with aSAH or controls. Hunt and Hess grade, Fisher grade, and the presence of hydrocephalus or vasospasm were not associated with the level of IGF-I concentration, either less than $11 \mathrm{nmol} /$ lor more than $11 \mathrm{nmol} / \mathrm{l}$.

In patients with aSAH, there were no differences in IGF-I or GH concentrations between the patients with respect to aneurysm location (anterior communicating artery versus others), treatment modality (clip vs. coil), Hunt-Hess grades (I to III versus IV to V), Fisher grade (I to II versus III to IV), Glasgow Coma Scale (GCS) (less than 8 or more than 8 ), symptomatic vasospasm and/or need for norepinephrine $(\mathrm{n}=9)$, or hydrocephalus on admission. Gender or body mass index did not affect IGF-I or GH concentrations. Age was negatively correlated with IGF-I $(\mathrm{r}=-0.31, P \leq 0.001)$.

The mean 15D HRQoL sum in patients with aSAH was $0.81 \pm 0.16$ and in control patients $0.86 \pm 0.09(P=0.24)$. Quality of life was moderately low $(<0.8)$ in six patients with aSAH and in five control patients $(P=0.75)$. In addition, three patients with aSAH and none of the control patients had poor quality of life $(<0.6)$. The HRQoL dimensions of speech $(P=0.04)$ and eating $(P=0.03)$ were lower in patients with aSAH than in the control group; otherwise, no statistically significant differences were observed in the scores between the groups. Ten patients in the aSAH group had a GOS of four or less, and the others had a GOS of five. Patients with a GOS of four or less had lower quality of life than patients with a GOS of five (0.7 vs.0.88, $P=0.003)$. Additionally, patients with a GOS of four or less had lower mean IGF-I concentrations than patients with a GOS of five $(8.3 \pm 2.6 \mathrm{nmol} / \mathrm{l} \mathrm{vs}$. $12.7 \pm 5.1 \mathrm{nmol} / \mathrm{l}, P=0.02$ ). Patients with Hunt \& Hess grades IV to $\mathrm{V}$ had similar HRQoL than patients with Hunt \& Hess grades I to III $(0.73 \pm 0.2$ vs. $0.84 \pm 0.13, P=$ $0.12)$. aSAH patients with low HRQoL $(<0.8)$ had lower mean IGF-I concentrations than patients with good HRQoL $(5.7 \pm 2.1 \mathrm{nmol} / \mathrm{l}$ vs. $8.7 \pm 3.4 \mathrm{nmol} / \mathrm{l})$. Mean IGFI for days one to seven was mildly associated with $\mathrm{HRQOL}$ by a Pearson's correlation coefficient of $0.36(P=0.08)$.

In the Bayesian model, use of statins prior to aSAH, hyponatremia, high maximal sequential organ specific score, and the sum of IGF results for days one to seven after the aSAH were associated with poor HRQoL. This model was accurate in $78.6 \%$ of cases in leave-one-out cross validation (corresponding log-score 0.57, compared with $53.6 \%$ accuracy for the biggest class (i.e., default or educated guess), log-score 0.69 ). When the model was tested by putting the total material into the model, an accuracy of $89 \%$ was reached. The sensitivity was 0.86 and specificity was 0.93 . The results indicate that a low 
Table 1: Patient demographics

\begin{tabular}{|c|c|c|c|c|c|}
\hline & $\begin{array}{c}\text { aSAH } \\
\text { Clipped } \\
(n=13)\end{array}$ & $\begin{array}{c}\text { aSAH } \\
\text { Coiled } \\
(n=17)\end{array}$ & $\begin{array}{l}P \text { value for } \\
\text { clipped vs. } \\
\text { coiled }\end{array}$ & Control $(n=16)$ & $\begin{array}{l}\text { Pvalue for aSAH vs. } \\
\text { controls }\end{array}$ \\
\hline Age, years (range) & $50(25-73)$ & $54(21-78)$ & 0.53 & $50(37-64)$ & 0.53 \\
\hline Gender M/F & $5 / 8$ & $9 / 8$ & 0.41 & $4 / 12$ & 0.15 \\
\hline \multicolumn{6}{|l|}{$\begin{array}{l}\text { Aneurysm } \\
\text { location }\end{array}$} \\
\hline ICA & 2 & 4 & & 6 & \\
\hline MCA & 8 & 0 & & 10 & \\
\hline$A C o A$ & 1 & 10 & & 0 & \\
\hline ACA distal & 1 & 1 & & 0 & \\
\hline VBA & 1 & 2 & & 0 & \\
\hline $\begin{array}{l}\text { Hydrocephalus at } \\
\text { admission }\end{array}$ & 2 & 4 & & 0 & \\
\hline \multicolumn{6}{|l|}{ Fisher grade } \\
\hline $\mid-I I$ & 2 & 2 & & & \\
\hline III-IV & 11 & 15 & & & \\
\hline \multicolumn{6}{|l|}{$\begin{array}{l}\text { Hunt and Hess } \\
\text { initial }\end{array}$} \\
\hline$|-I|$ & 5 & 10 & & & \\
\hline III & 3 & 3 & & & \\
\hline IV-V & 5 & 4 & & & \\
\hline SAPS ॥ & $27 \pm 12$ & $33 \pm 14$ & 0.27 & & \\
\hline APACHE II & $14 \pm 5$ & $16 \pm 6$ & 0.53 & & \\
\hline
\end{tabular}

Data are presented as numbers or mean \pm standard deviation unless otherwise indicated.

aSAH clipped, patients with their ruptured aneurysm treated by open surgical clipping, aSAH coiled, patients with their ruptured aneurysm treated by endovascular coiling. ACA, anterior cerebral artery; AcoA, anterior communicating artery; APACHE, Acute Physiology and Chronic Health Evaluation; ICA, internal carotid artery; MCA, median cerebral artery; SAH, subarachnoid hemorrhage; SAPS, Simplified Acute Physiology Score; VBA, vertebro basilar artery.

IGF level in the days following aSAH may be associated with poor HRQoL or death.

\section{Discussion}

To the best of our knowledge, this is the first study to evaluate the behavior of IGF-I in the acute phase of aSAH, and to combine it with GOS and HRQoL assessment at three months. According to our study, serum IGF-I levels are low during acute aSAH, but they normalize at three months. The results may reflect diminished acute pituitary function. The severity of aSAH does not influence serum IGF-I levels. Quality of life at three months was equal in patients with acute alive aSAH at three months and patients who underwent elective surgery for unruptured aneurysms. However, low IGF-I values, measured acutely after aSAH, may predict morbidity assessed by GOS and HRQoL.

aSAH may cause various long-lasting neurological deficits and disturbances in mental health, sleep, concentra- tion capability, anxiety, and depression [24]. These symptoms are thought to be caused by aSAH-related ischemic lesions. There is some evidence showing pituitary function deficits may affect quality of life years after aSAH [9]. A GH deficiency might adversely affect vitality, sleep, and fatigue dimensions of quality of life. Although the mean quality of life was similar in patients with aSAH and control patients, patients with aSAH had depressed quality of life in eating and speech. Those aSAH patients with cumulative low IGF-I concentrations are at risk for low quality of life and increased morbidity, which may support the theory of the imperative role of IGF-I in the acute phase of neurological brain injury [15]. The role of IGF-I in the recovery of aSAH is not well studied; however, it is known that aSAH causes various long-lasting deficits in quality of life [24]. In our study, we found an association between IGF-I and HRQoL and hypothesize, but cannot demonstrate, that this is causal. 


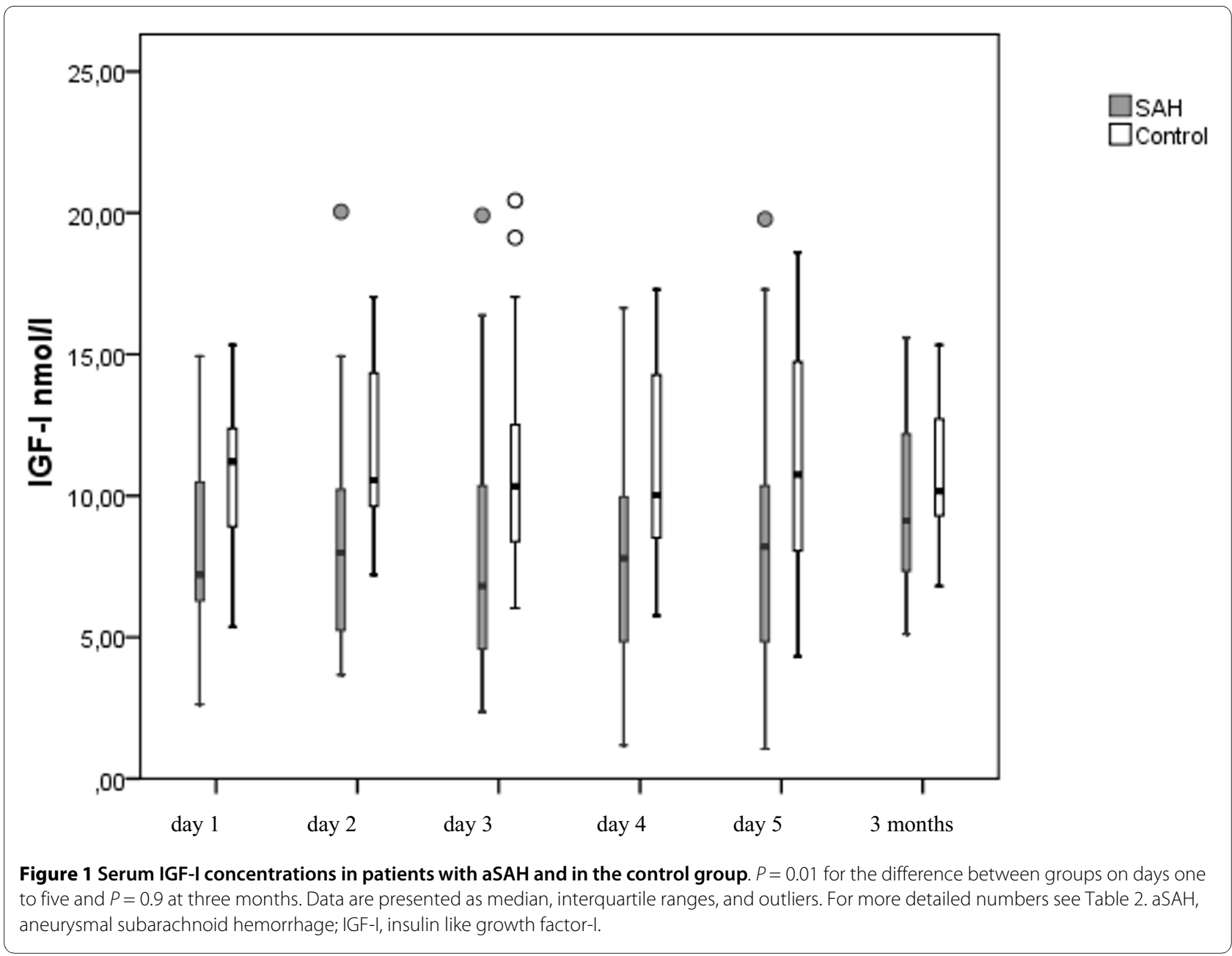

In the context of aSAH, it is most interesting that IGF-I presents with major vascular effects, and thus may contribute to the pathophysiological processes in aSAH [25].

Serum IGF-I is essential in mediating GH action. During critical illness, serum levels of IGF-I may decrease substantially [14]. There is increasing evidence that IGF-I has an essential role in neuronal growth, regeneration, and apoptotic cell death, and in adaptation to brain ischemia [10-12,15]. All these mechanisms may also be involved in acute aSAH [13]. In ischemic stroke, as well as meningococcal sepsis, low IGF-I concentrations may predict poor outcome in humans $[15,26]$. Surgical stress and

Table 2: GH and IGF-I concentrations at different time points

\begin{tabular}{lllllll}
\hline GH (mU/I) & aSAH & Control & P value & $\begin{array}{l}\text { IGF-I (nmol/I) } \\
\text { aSAH }\end{array}$ & Control & P value \\
\hline day1 & $3.4 \pm 5.5$ & $1.6 \pm 2.7$ & 0.18 & $8.2 \pm 3.1$ & $10.5 \pm 2.7$ & 0.04 \\
day2 & $3.5 \pm 5.5$ & $4.5 \pm 5.3$ & 0.48 & $8.4 \pm 3.6$ & $11.9 \pm 3.1$ & $<0.01$ \\
day3 & $3.0 \pm 5.3$ & $1.8 \pm 1.6$ & 0.37 & $8.1 \pm 4.2$ & $11.4 \pm 4.2$ & $<0.01$ \\
day4 & $2.4 \pm 4$ & $3.5 \pm 4.5$ & 0.54 & $7.8 \pm 3.9$ & $10.9 \pm 3.8$ & 0.01 \\
day5 & $2.0 \pm 2.1$ & $2.4 \pm 3.7$ & 0.72 & $8.0 \pm 4.4$ & $11.1 \pm 4.1$ & $<0.01$ \\
day6 & $2.1 \pm 2.4$ & & & $7.8 \pm 4.0$ & & \\
day7 & $1.6 \pm 2.4$ & & & $7.7 \pm 4.0$ & & \\
3 months & $2.0 \pm 5.1$ & $3.7 \pm 5.0$ & 0.23 & $9.7 \pm 3.1$ & & \\
\hline
\end{tabular}

Data are presented as mean values \pm standard deviations.

aSAH, aneurysmal subarachnoid hemorrhage;GH, growth hormone; IGF-I: Insulin like growth factor-I. 


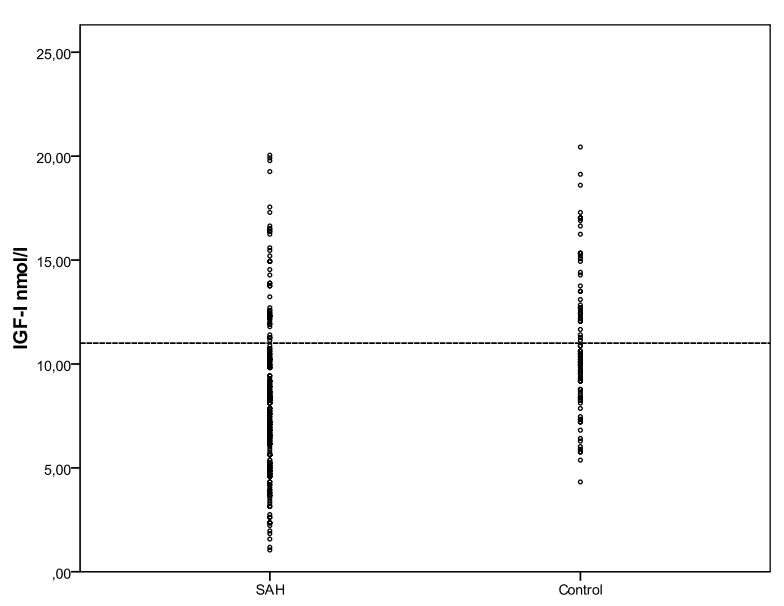

Figure 2 Pooled IGF-I concentrations in patients with aSAH and in the control group. The line represents the cut-off level of $11 \mathrm{nmol} /$ I. The insulin like growth factor-I (IGF-I) concentration was below 11 $\mathrm{nmol} / \mathrm{l}$ on day one in $77 \%$ of aneurysmal subarachnoid hemorrhage (aSAH) patients and in 23\% ( $P=0.02)$ of control patients. The respective values were $74 \%$ and $27 \%(P=0.05)$ on day two, $70 \%$ and $30 \%(P=0.3)$ on day three, $72 \%$ and $28 \%(P=0.22)$ on day four, and $74 \%$ and $27 \%(P$ $=0.05$ ) on day five. In the aSAH group, $83 \%$ of patients on day six and $76 \%$ on day seven had IGF-concentrations below $11 \mathrm{nmol} / \mathrm{I}$. At three months, no patient had IGF-concentrations lower than $11 \mathrm{nmol} / \mathrm{l}$.

brain manipulation in the control group were not associated with a decrease in IGF-I concentrations, as in patients with aSAH, regardless of the severity. Several factors other than $\mathrm{GH}$ secretion, for example nutritional status, may affect IGF-I concentrations [27]. Therefore, low IGF-I is not always associated with GH deficiency per se [28].

Low IGF-I concentrations in aSAH may reflect either pituitary GH insufficiency, decreased liver production, or a stress-related decrease of IGF-I concentrations in critical illness. An essential percentage of aSAH patients had IGF concentrations far below the age-related reference values. It was shown previously that a disturbance in the function of the GH-IGF axis is the first pituitary deficiency to appear after aSAH or TBI $[4,29]$. The mechanisms are not fully understood, but the vulnerable and complex vasculature of the pituitary gland may easily be affected by severe brain insults.

The role of single IGF-I concentration measurement may be controversial. It is generally accepted that definitive GH insufficiency should be tested by means of a stimulation test [30]. Concentrations of IGF-I less than 10 $\mathrm{nmol} / \mathrm{l}$ have a specificity of $95 \%$, but a sensitivity of only $40 \%$ in diagnosing GH deficiency [31]. In our study, the IGF-I concentrations were often far lower than this threshold. There are numerous cut-off points for IGF-I in screening for GH deficiency [19,28,32]. However, it is not known how high concentrations of IGF-I could be neuroprotective in acute intracranial neurological catastrophes.
In our study, GH concentrations and IGF-I concentrations did not correlate with each other. GH concentrations vary a lot during critical illness; the pulsatile secretion of GH makes adequate interpretation of serum concentrations of GH especially difficult. In the present study, GH concentrations were equal in patients with $\mathrm{aSAH}$ and the control patients. In the literature, there are no data on $\mathrm{GH}$ concentrations in the acute phase of aSAH. At the later phase, after aSAH, GH insufficiency may appear in $25 \%$ of patients [4].

There are some limitations in our study. We did not use the GH stimulation test when diagnosing GH deficiency. However, as described above, IGF-I itself has an essential role in acute neurological diseases $[11,12]$. The method used for measuring IGF-I may also influence the results [27]. Although our sample size was small, the aSAH was well defined by the onset and type of bleeding. The control group may be criticized because it consisted of patients undergoing open cranial surgery; that is, patients exposed to similar kinds of stress as those with aSAH. However, using other ICU patients as the control group might have caused other confounding factors, such as infections and hemodynamic instability.

We propose that it might also be argued that the method of securing the ruptured aneurysm in the aSAH group could markedly effect the results. However, severity of the bleeding and the level of consciousness on admission are by far the most important prognostic factors in aSAH and the treatment modality is of lesser importance $[33,34]$. As expected, there were no differences in IGF-I or GH concentrations between the patients with respect to treatment modality. If surgery had an effect, the surgical patients in the control would compensate this effect on IGF-I in comparisons between the control and aSAH groups.

IGF-I may be one factor among multiple others in influencing outcome in patients with aSAH. Larger studies are needed to prove the causality of this finding.

\section{Conclusions}

Serum IGF-I concentrations are low in patients with acute aSAH, which may affect morbidity in these patients. The severity of aSAH did not affect IGF-I concentrations. Larger studies are needed to evaluate the neuroprotective role of IGF-I in aSAH.

\section{Key messages}

- IGF-I has an important role in neuronal growth and cell death

- Serum IGF-I concentrations are low in the acute phase of aSAH

- Low IGF-I concentrations may reflect acute pituitary insufficiency in patients with aSAH 


\section{- Low IGF-I concentrations may affect morbidity in patients with aSAH}

\section{Abbreviations}

aSAH: aneurysmal subarachnoid hemorrhage; ELISA: enzyme-linked immunosorbent assay; GH: growth hormone; GCS: Glasgow Coma Scale; GOS: Glasgow outcome scale; HDU: high-dependency unit; HPA: hypothalamo-pituitary-adrenal; HRQoL: health-related quality of life; IGF-I: insulin-like growth factor-l; LOS: length of stay; TBI: traumatic brain injury.

\section{Competing interests}

The authors declare that they have no competing interests.

\section{Authors' contributions}

SB, AU and TK participated in study conception, acquisition of data, analysis and interpretation of data, drafting the manuscript and revising it critically. OR participated in analysis and interpretation of data, drafting the manuscript and revising it critically. ER, JRO and VK participated in analysis and interpretation of data.

\section{Author Details}

1 Department of Intensive Care, Kuopio University Hospital and University of Eastern Finland, PL 1777, 70211 Kuopio, Finland, 2Department of Neurosurgery, Kuopio University Hospital and University of Eastern Finland, PL 1777, 70211 Kuopio, Finland, ${ }^{3}$ Department of Public Health, University of Eastern Finland, Asemakatu 44 A 4, 70100 Kuopio, Finland, 4Eastern Finland Laboratory Centre, Kuopio University Hospital, PL1777, 70211 Kuopio, Finland and 5 IT Centre, Statistical and mathematical sciences, University of Eastern Finland PL 1627 70211 Kuopio, Finland

Received: 6 November 2009 Revised: 21 February 2010

Accepted: 28 April 2010 Published: 28 April 2010

\section{References}

1. Nieuwkamp DJ, Setz LE, Algra A, Linn FH, de Rooij NK, Rinkel GJ: Changes in case fatality of aneurysmal subarachnoid haemorrhage over time, according to age, sex, and region: a meta-analysis. Lancet Neurol 2009, 8:635-642.

2. Schneider HJ, Kreitschmann-Andermahr I, Ghigo E, Stalla GK, Agha A: Hypothalamopituitary dysfunction following traumatic brain injury and aneurysmal subarachnoid hemorrhage: a systematic review. JAMA 2007, 298:1429-1438.

3. Bendel S, Koivisto T, Ruokonen E, Rinne J, Romppanen J, Vauhkonen I, Kiviniemi V, Uusaro A: Pituitary-adrenal function in patients with acute subarachnoid haemorrhage: A prospective cohort study. Crit Care 2008, 12:R126.

4. Aimaretti G, Ambrosio MR, Di Somma C, Fusco A, Cannavo S, Gasperi M, Scaroni C, De Marinis L, Benvenga S, Degli Uberti EC, Lombardi G, Mantero F, Martino E, Giordano G, Ghigo E: Traumatic brain injury and subarachnoid haemorrhage are conditions at high risk for hypopituitarism: Screening study at 3 months after the brain injury. Clin Endocrinol (Oxf) 2004, 61:320-326.

5. Espiner EA, Leikis R, Ferch RD, MacFarlane MR, Bonkowski JA, Frampton CM, Richards AM: The neuro-cardio-endocrine response to acute subarachnoid haemorrhage. Clin Endocrinol (Oxf) 2002, 56:629-635.

6. Kelly DF, Gonzalo IT, Cohan P, Berman N, Swerdloff R, Wang C: Hypopituitarism following traumatic brain injury and aneurysmal subarachnoid hemorrhage: a preliminary report. J Neurosurg 2000, 93:743-752

7. Brandt L, Saveland H, Valdemarsson S, Sjoholma H, Reinsturp P: Fatigue after aneurysmal subarachnoid hemorrhage evaluated by pituitary function and 3D-CBF. Acta Neuro/ Scand 2004, 109:91-96.

8. Tanriverdi F, Dagli AT, Karaca Z, Unluhirzarci K, Selcuklu A, Casanueva FF, Kelestimur F: High risk of pituitary dysfunction due to aneurysmal subarachnoid haemorrhage: A prospective investigation of anterior pituitary function in the acute phase and 12 months after the event. Clin Endocrinol (Oxf) 2007, 67:931-937.

9. Kreitschmann-Andermahr I, Poll E, Hutter BO, Reineke A, Kristes S, Gilsbach JM, Saller B: Quality of life and psychiatric sequelae following aneurysmal subarachnoid haemorrhage: Does neuroendocrine dysfunction play a role? Clin Endocrinol (Oxf) 2007, 66:833-837.
10. Kooijman R: Regulation of apoptosis by insulin-like growth factor (IGF)I. Cytokine Growth Factor Rev 2006, 17:305-323.

11. Kooijman R, Sarre S, Michotte Y, De Keyser J: Insulin-like growth factor I. A potential neuroprotective compound for the treatment of acute ischemic stroke? Stroke 2009, 40:e83-88.

12. Aleman A, Torres-Alemán I: Circulating insulin-like growth factor I and cognitive function: Neuromodulation throughout the lifespan. Prog Neurobiol 2009, 89:256-265.

13. Cahill J, Calvert JW, Zhang JH: Mechanisms of early brain injury after subarachnoid hemorrhage. J Cereb Blood Flow Metab 2006, 26:1341-1353.

14. Baxter RC, Hawker FH, To C, Steward PM, Holman SR: Thirty-day monitoring of insulin-like growth factors and their binding proteins in intensive care unit patients. Growth Horm IGF Res 1998, 8:455-463.

15. Bondanelli M, Ambrosio MR, Onofri A, Bergonzoni A, Lavezzi S, Zatelli MC, Valle D, Basaglia N, Degli Uberti EC: Predictive value of circulating insulin-like growth factor I levels in ischemic stroke outcome. J Clin Endocrinol Metab 2006, 91:3928-3934.

16. Denti L, Annoni V, Cattadori E, Salvagnini MA, Visioli S, Merli MF, Corradi F, Ceresini G, Valentini G, Hoffman AR, Ceda GP: Insulin-like growth factor 1 as a predictor of ischemic stroke outcome in the elderly. Am J Med 2004, 117:312-317.

17. van Rijn MJ, Slooter AJ, Bos MJ, Catarino CF, Koudstaal PJ, Hofman A, Breteler MM, van Duijn CM: Insulin-like growth factor I promoter polymorphism, risk of stroke, and survival after stroke: The rotterdam study. J Neurol Neurosurg Psychiatry 2006, 77:24-27

18. Sintonen $\mathrm{H}$ : The $15 \mathrm{D}$ instrument of health-related quality of life: properties and applications. Ann Med 2001, 33:328-336.

19. Hartman ML, Crowe BJ, Biller BM, Ho KK, Clemmons DR, Chipman JJ, Hypos CCS Advisory Board, U.S. HypoCCS Study Group: Which patients do not require a GH stimulation test for the diagnosis of adult $\mathrm{GH}$ deficiency? J Clin Endocrinol Metab 2002, 87:477-485.

20. 15d-instrument [http://www.15d-instrument.net/15d

21. Mattila AK, Saarni SI, Salminen JK, Huhtala H, Sintonen H, Joukamaa M: Alexithymia and health-related quality of life in a general population. Psychosomatics 2009, 50:59-68.

22. Soini E, Rissanen T, Tiihonen J, Hodgins S, Eronen M, Ryynänen O-P: Predicting forensic admission among the mentally ill in a multinational setting: a Bayesian modelling approach. Volume 68. Data \& Knowledge Engineering: 2009:1427-1440.

23. $\mathrm{Ng}$ AY, Jordan MI: On discriminative vs. generative classifiers: a comparison of logistic regression and naive bayes. Edited by: Dietterich T, Becker S, Ghahramani Z. Cambridge, MIT press; 2002.

24. Visser-Meily JM, Rhebergen ML, Rinkel GJ, van Zandvoort MJ, Post MW: Long-term health-related quality of life after aneurysmal subarachnoid hemorrhage: relationship with psychological symptoms and personality characteristics. Stroke 2009, 40:1526-1529.

25. Juul A, Scheike T, Davidsen M, Gyllenborg J, Jorgensen T: Low serum insulin-like growth factor I is associated with increased risk of ischemic heart disease: a population-based case-control study. Circulation 2002, 106:939-944.

26. de Groof F, Joosten KF, Janssen JA, de Kleijn ED, Hazelnet JA, Hop WC, Uitterlinden $\mathrm{P}$, van Doorn J, Hokken-Koelega AC: Acute stress response in children with meningococcal sepsis: Important differences in the growth hormone/insulin-like growth factor I axis between nonsurvivors and survivors. J Clin Endocrinol Metab 2002, 87:3118-3124.

27. Brabant $G$, Wallaschofski H: Normal levels of serum IGF-I: Determinants and validity of current reference ranges. Pituitary 2007, 10:129-133.

28. Aimaretti G, Ambrosio MR, Di Somma C, Gasperi M, Cannavo S, Scaroni C, Fusco A, Del Monte P, De Menis E, Faustini-Fustini M, Grimaldi F, Logoluso F, Razzore P, Rovere S, Benvenga S, Degli Uberti EC, De Marinis L, Lombardi G, Mantero F, Martino F, Martino E, Giordano G, Ghigo E: Residual pituitary function after brain injury-induced hypopituitarism: a prospective 12-month study. J Clin Endocrinol Metab 2005, 90:6085-6092

29. Popovic V: GH deficiency as the most common pituitary defect after TBI: clinical implications. Pituitary 2005, 8:239-243.

30. Gasco V, Corneli G, Rovere S, Croce C, Beccuti G, Mainolfi A, Grottoli S, Aimaretti G, Ghigo E: Diagnosis of adult GH deficiency. Pituitary 2008, 11:121-128

31. Biller BM, Samuels MH, Zagar A, Cook DM, Arafah BM, Bonert V, Stavrou S, Kleinberg DL, Chipman JJ, Hartman ML: Sensitivity and specificity of six 
tests for the diagnosis of adult GH deficiency. J Clin Endocrinol Metab 2002, 87:2067-2079.

32. Ghigo E, Masel B, Aimaretti G, Leon-Carrion J, Casanueva FF, DominguezMorales MR, Elovic E, Perrone K, Stalla G, Thompson C, Urban R:

Consensus guidelines on screening for hypopituitarism following traumatic brain injury. Brain Inj 2005, 19:711-724.

33. Koivisto T, Vanninen R, Hurskainen H, Saari T, Hernesniemi J, Vapalahti M: Outcomes of early endovascular versus surgical treatment of ruptured cerebral aneurysms. A prospective randomized study. Stroke 2000, 31:2369-2377

34. O'Kelly CJ, Kulkarni AV, Austin PC, Wallace MC, Urbach D: The impact of therapeutic modality on outcomes following repair of ruptured intracranial aneurysms: an administrative data analysis. J Neurosurg 2009 in press.

\section{doi: $10.1186 / \mathrm{cc} 8988$}

Cite this article as: Bendel et al., Insulin like growth factor-l in acute subarachnoid hemorrhage: a prospective cohort study Critical Care 2010, 14:R75

Submit your next manuscript to BioMed Central and take full advantage of:

- Convenient online submission

- Thorough peer review

- No space constraints or color figure charges

- Immediate publication on acceptance

- Inclusion in PubMed, CAS, Scopus and Google Scholar

- Research which is freely available for redistribution

Submit your manuscript at www.biomedcentral.com/submit
C) Biomed Central 